\title{
AVALIAÇÃO DA ESTABILIDADE TERMO-OXIDATIVA DO BIODIESEL DE CANOLA ADITIVADO COM EXTRATOS NATURAIS
}

\author{
N. S. SUVEGES ${ }^{1}$ e M. L.C. P. da SILVA ${ }^{1}$ \\ ${ }^{1}$ Universidade de São Paulo, Departamento de Engenharia Química \\ E-mail para contato: nsiktar@yahoo.com.br
}

\begin{abstract}
RESUMO - A utilização de antioxidantes sintéticos nas indústrias de biocombustíveis com o intuito de se prolongar a vida útil destes materiais é comum, porém com a finalidade de se utilizar o maior número de matérias-primas renováveis no processo do biodiesel é que surgiu a ideia de estudar a adição de extratos naturais, pois estes são ricos em compostos fenólicos, os principais responsáveis pela ação antioxidante. Neste trabalho foi avaliada a ação dos extratos provenientes da casca de laranja, erva mate e das folhas de alecrim no biodiesel de canola o qual foi exposto ao aquecimento durante o período de 60 dias. A técnica utilizada para se avaliar a estabilidade termo-oxidativa foi a termogravimetria (TGA), fazendo-se o acompanhamento da temperatura inicial de degradação (Ti) para a certificação da efetividade das adições. Ao final, constatou-se que as melhores adições ocorreram com a concentração de $2.000 \mathrm{mg} / \mathrm{L}$, e dentre estas o extrato da casca de laranja apresentou o melhor resultado.
\end{abstract}

\section{INTRODUÇÃO}

A energia é um fator essencial para a humanidade continuar com o desenvolvimento econômico e manter o alto padrão de vida obtido principalmente após a revolução industrial no século XVIII e próximo do século XIX. De acordo com a Agência Internacional de Energia (IEA), o mundo necessitará de mais de 50\% de energia em 2030 que hoje, as quais $45 \%$ serão consumidas pela China e Índia. Globalmente o setor de transporte é o segundo maior consumidor de energia (perdendo somente para o setor industrial) correspondendo a $30 \%$ do total mundial consumido, das quais $80 \%$ são destinados ao transporte rodoviário (ATABANI et al., 2012).

A maior parte do consumo de energia do mundo provém de matérias-primas fósseis como o petróleo, carvão e gás natural, sendo crescente o consumo do petróleo e gás natural no decorrer dos anos. No entanto, estas fontes não renováveis de energia poderão se esgotar futuramente e, sendo assim, a procura por fontes renováveis e sustentáveis de energia tem ganhado destaque para solucionar assuntos atuais, como o aumento do preço do petróleo bruto e questões ambientais como a poluição do ar e o aquecimento global causado pela queima destes combustíveis (KOH; GHAZI, 2011). 


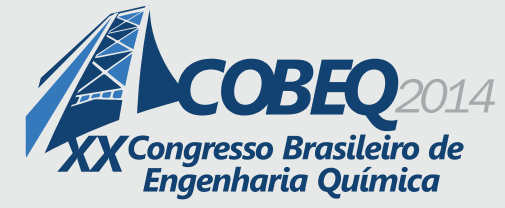

Uma das opções de energias renováveis é o biodiesel, que é obtido principalmente a partir de fontes vegetais e animais, porém atentando-se para as diversas variáveis que interferem na qualidade deste biocombustível. A pureza e a qualidade do biodiesel podem ser significativamente influenciadas por diversos fatores dentre eles incluem: a qualidade da matéra-prima, composição do ácido graxo do óleo vegetal, gordura animal e óleos residuais utilizados, tipo de processo empregado e os parâmetros pós-produção (ATADASHI; AROUA; AZIZ, 2010).

Dentre as desvantagens para a produção do biodiesel está a menor estabilidade oxidativa em relação ao diesel mineral, devido a presença das ligações insaturadas nas cadeias carbônicas provenientes dos ácidos graxos da matéria-prima, que podem comprometer a armazenagem e utilização do biocombustível. Em muitos casos essa desvantagem pode ser superada pela utilização de antioxidantes, compostos que podem inibir ou retardar o processo de oxidação do biocombustível (SILVA, 2005).

Além do prolongamento da vida útil do biodiesel, a importância do estudo da estabilidade oxidativa está relacionada ao fato de que o combustível oxidado tem a sua viscosidade aumentada, com formação de incrustações no injetor e depósitos na câmara de combustão e em vários componentes do sistema de combustão, o que leva a um desempenho ineficiente do motor (JAIN; SHARMA, 2010).

Diante desse cenário e da importância do biocombustível, a proposta deste trabalho é o estudo do comportamento da aditivação do biodiesel de canola com extratos naturais com o intuito de prolongar as suas propriedades termo-oxidativa. As adições foram realizadas com $1.000 \mathrm{mg} / \mathrm{L} \mathrm{e}$ $2.000 \mathrm{mg} / \mathrm{L}$ de extratos de folha de alecrim, casca de laranja e erva mate e os biodieseis aditivados foram expostos a temperatura de $60^{\circ} \mathrm{C}$, em uma estufa, sendo a efetividade dessas adições acompanhadas no período de 60 dias com o auxílio da termogravimetria.

\section{MATERIAIS E MÉTODOS}

\subsection{Síntese do biodiesel metílico de canola}

Em um reator de vidro encamisado com capacidade para $300 \mathrm{~mL}$ e com agitador de pás duplas, adicionou-se $100 \mathrm{~g}$ do óleo vegetal de canola e em seguida uma solução de metóxido de potássio (metanol $+\mathrm{KOH}$ ) para a reação de transesterificação. A razão molar utilizada de metanol para o óleo vegetal foi de 5:1 e a razão molar de óleo vegetal para o $\mathrm{KOH}$ foi de 1:0,13.

$\mathrm{O}$ reator foi previamente aquecido à $58^{\circ} \mathrm{C}$ contendo o óleo vegetal sob agitação moderada. A reação de transesterificação ocorreu em 45 minutos. Na sequência, transferiu-se a solução do reator para um funil de separação, deixando a solução em repouso e então o glicerol foi separado do biodiesel. A purificação ocorreu em um béquer sob agitação lenta, adicionando água destilada com o auxílio de uma bureta volumétrica. O biodiesel foi novamente transferido para um funil de separação e permanecendo em repouso. A fase aquosa foi separada do biodiesel e este foi encaminhado para uma estufa a $100^{\circ} \mathrm{C}$ durante 1 hora para a retirada do excesso de água (PAIVA, 2010). 


\subsection{Obtenção dos extratos vegetais}

As cascas de laranja e as folhas de alecrim utilizadas neste trabalho foram secas em estufa a $30{ }^{\circ} \mathrm{C}$ por uma semana para a retirada do excesso de umidade e a erva mate foi utilizada in natura assim como podem ser visualizadas. As cascas de laranja antes de serem secas foram limpas para a retirada do bagaço residual (parte branca e bagaço) e posteriormente trituradas em um moinho manual. A partir destes produtos vegetais foram obtidos os extratos vegetais, a patir do método Soxhlet, e então utilizados nos biodiesel que foi exposto a temperatura de $60{ }^{\circ} \mathrm{C}$.

O método Soxhlet consiste em um tipo de extração sólido-líquido muito utilizado para obtenção de um extrato vegetal. Para a obtenção dos extratos primeiramente pesou-se $10,00 \mathrm{~g}$ das folhas de alecrim, casca de laranja ou erva mate em um béquer. $\mathrm{O}$ material pesado foi colocado em papel de filtro enrolado na forma de cartucho e em seguida colocado no extrator Soxhlet. Antes de acoplar o extrator ao condensador adicionou-se o diclorometano no extrator até que o cartucho ficasse totalmente submerso no solvente. Em seguida adicionou-se ao balão de $250 \mathrm{~mL}$, aproximadamente $150 \mathrm{~mL}$ do solvente orgânico e conectou-se o extrator Soxhlet. O sistema ficou sob aquecimento $\left(40{ }^{\circ} \mathrm{C}\right)$ por aproximadamente duas horas e meia. Após este período, interrompeu-se a extração exatamente após o esvaziamento da câmara de extração. Retirou-se o cartucho contendo a amostra e reaqueceu-se até que a câmara de extração estivesse quase cheia. Remontou-se o aparelho e repetiu a operação de destilação do solvente até que o balão ficasse quase seco. Desligou-se o aquecimento, aguardou-se o tempo para esfriar o balão e o desconectou para retirada do extrato de interesse (PALLEROS, 1999).

\subsection{Aditivações}

Os extratos vegetais, das folhas de alecrim, casca de laranja e erva mate, foram adicionados ao biodiesel nas concentrações de $1.000 \mathrm{mg} / \mathrm{L}$ e $2.000 \mathrm{mg} / \mathrm{L}$ e solubilizados em um frasco de Erlenmeyer com o auxílio de um agitador magnético (Figura 1). Na sequência, o biodiesel foi exposto a temperatura de $60^{\circ} \mathrm{C}$, em uma estufa, durante 60 dias.

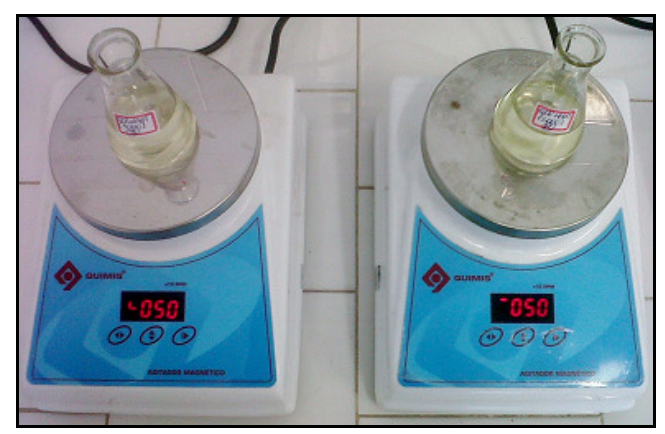

Figura 1 - Sistema utilizado para solubilização dos aditivos. 


\subsection{Métodos de análise}

\subsubsection{Massa específica, viscosidade cinemática e índice de acidez}

O biodiesel de canola sintetizado neste trabalho foi caracterizado quanto a massa específica, viscosidade cinemática e índice de acidez e somente após a obtenção destes resultados é que o biodiesel foi aditivado com os extratos vegetais.

\subsubsection{Termogravimetria (TGA)}

A temogravimetria do biodiesel envolvido neste trabalho foi realizada em uma termobalança modelo TGA-50 marca SHIMADZU, para se determinar a perda de massa dos compostos quando submetidos a uma taxa de aquecimento constante durante um intervalo de temperatura. $\mathrm{O}$ perfil da degradação térmica foi investigado no intervalo desde a temperatura ambiente até $600{ }^{\circ} \mathrm{C}$, com taxa de aquecimento $10^{\circ} \mathrm{C} / \mathrm{min}$, com um fluxo de ar sintético de $50 \mathrm{~mL} / \mathrm{min}$.

\section{RESULTADOS E DISCUSSÕES}

\subsection{Resultados do biodiesel de canola}

A Tabela 1 apresenta os resultados do índice de acidez, densidade e da viscosidade com o intuito de se verificar a conformidade com os parâmetros da resolução ANP n ${ }^{\circ} 14$ de 11.5.2012.

Tabela 1 - Especificação do biodiesel e resultados do biodiesel de canola.

\begin{tabular}{cc}
\hline ESPECIFICAÇÃO BIODIESEL & B100 CANOLA \\
\hline Massa específica a $20^{\circ} \mathrm{C}\left(850\right.$ a $\left.900 \mathrm{~kg} / \mathrm{m}^{3}\right)$ & 880 \\
Viscosidade cinemática a $40^{\circ} \mathrm{C}\left(3,0\right.$ a $\left.6,0 \mathrm{~mm}^{2} / \mathrm{s}\right)$ & 4,8 \\
Índice de acidez, máx. 0,50 $\mathrm{mg} \mathrm{KOH} / \mathrm{g}$ & 0,10
\end{tabular}

Pela Tabela 1 observa-se que todas as características analisadas apresenta-se em conformidade com a especificação da ANP o que permitiu a continuidade dos estudos através das adições com extratos naturais.

Ao observarmos a curva TGA, Figura 2, determinou-se que o biodiesel de canola apresenta os valores de Ti igual a $201{ }^{\circ} \mathrm{C}$ e curva DTG mostra temperatura de maior velocidade de perda de massa em $244{ }^{\circ} \mathrm{C}$. 


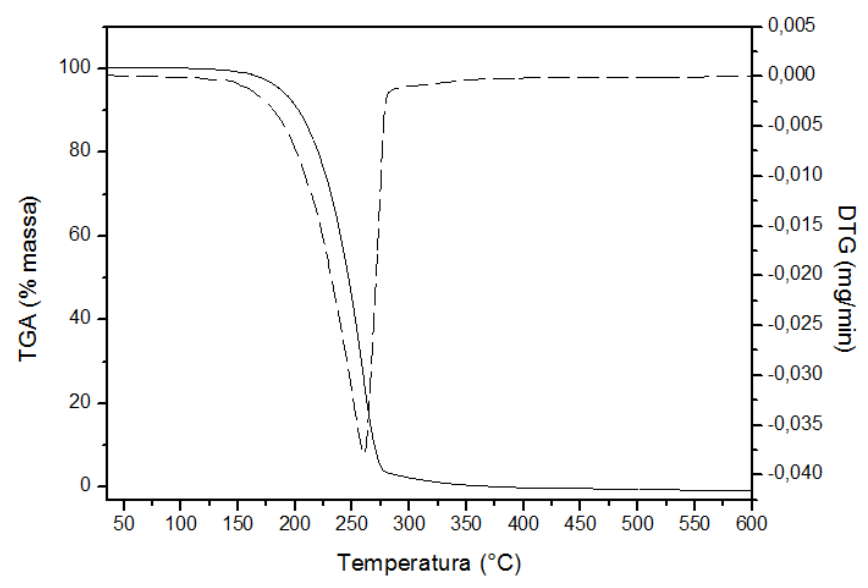

Figura 2 - TGA/DTG do B100 de canola.

\subsection{TGA do B100 de canola com extratos da casca de laranja, erva mate e folhas de alecrim exposto à temperatura de $60^{\circ} \mathrm{C}$}

Nesta etapa do trabalho o biodiesel foi exposto a condição de oxidação juntamente com os extratos dos produtos vegetais adicionados a ele. Para isso utilizou-se a extração Soxhlet para obtenção dos extratos naturais concentrados das folhas de alecrim, casca de laranja e erva mate. $\mathrm{O}$ biodiesel de canola foi colocado em frascos de Erlenmeyer de $125 \mathrm{~mL}$ e a ele adicionou-se 1.000 $\mathrm{mg} / \mathrm{L} \mathrm{e} 2.000 \mathrm{mg} / \mathrm{L}$ dos extratos naturais. Os aditivos naturais foram solubilizados nos biodieseis com o auxílio de um agitador magnético e após a solubilização montou-se a condição de estudo. Os frascos contendo as amostras foram colocados abertos e submetidos à temperatura de $60{ }^{\circ} \mathrm{C} \mathrm{em}$ uma estufa. Todas as amostras foram avaliadas no decorrer de 60 dias por termogravimetria.

Os melhores valores da Ti foram para os produtos com concentração de $2.000 \mathrm{mg} / \mathrm{L}$ de antioxidantes, ou seja, apresentando valores mais próximos do Ti do B100 de canola antes da exposição a condição de oxidação. Dentre os produtos aditivados o melhor resultado encontrado foi para o biodiesel com extrato da casca de laranja, com valor de $\mathrm{Ti}=195^{\circ} \mathrm{C}$ no $60^{\circ}$ dia, conforme pode ser visto na Tabela 2. Isto pode ser justificado principalmente pela presença dos flavonoides e ácidos fenólicos, dentre eles a hesperidina, naringina e ácido cafeico, que atuam como bons doadores de $\mathrm{H}$ (hidrogênio) para os radicais livres presentes nas amostras (ANAGNOSTOPOULOU et al., 2005). 
Tabela 2 - Valores de Ti do B100 de canola exposto a temperatura de $60{ }^{\circ} \mathrm{C}$.

\begin{tabular}{|c|c|c|c|}
\hline \multicolumn{4}{|c|}{$\mathrm{Ti}\left({ }^{\circ} \mathrm{C}\right)$} \\
\hline Período & 7 dias & 30 dias & 60 dias \\
\hline B100 CANOLA & 200 & 193 & 188 \\
\hline CANOLA + ALECRIM (1000) & 203 & 190 & 190 \\
\hline CANOLA + ALECRIM (2000) & 201 & 201 & 193 \\
\hline CANOLA + CASCA LAR (1000) & 201 & 189 & 190 \\
\hline CANOLA + CASCA LAR (2000) & 201 & 196 & 195 \\
\hline CANOLA + ERVA MATE $(\mathbf{1 0 0 0})$ & 201 & 191 & 187 \\
\hline CANOLA + ERVA MATE (2000) & 201 & 196 & 192 \\
\hline
\end{tabular}

O perfil da curva termogravimétrica do B100 puro apresentou os seguintes eventos térmicos no decorrer dos 60 dias: um evento térmico após 7 dias de exposição, 2 eventos após 30 dias e 3 eventos após 60 dias. As amostras com $2.000 \mathrm{mg} / \mathrm{L}$ de aditivos apresentaram valores de Ti melhores, ou seja, valores mais próximos da Ti do B100 antes da exposição a condição de oxidação e o perfil termogravimétrico destas amostras se apresentou de semelhante entre elas no $60^{\circ}$ dia e o B100 puro apresentou um adiantamento na ocorrência dos eventos térmicos e que pode ser melhor visualizado na Figura 3.

Das amostras que continham 2 e 3 eventos térmicos, o $2^{\circ}$ evento se iniciou em média na temperatura de $280{ }^{\circ} \mathrm{C}$ e as amostras com 3 eventos, o inicio foi por volta $450{ }^{\circ} \mathrm{C}$ (temperatura em que se tem o término do $2^{\circ}$ evento térmico). Estes eventos térmicos provavelmente correspondem à degradação dos ácidos graxos insaturados, saturados e dos produtos secundários da oxidação (como os polímeros) o que está em concordância com os estudos realizados por Chai (2012), em que relata que a energia de ativação dos ésteres metílicos insaturados são menores do que as dos ésteres metílicos saturados e consequentemente decompõem mais rápido. 


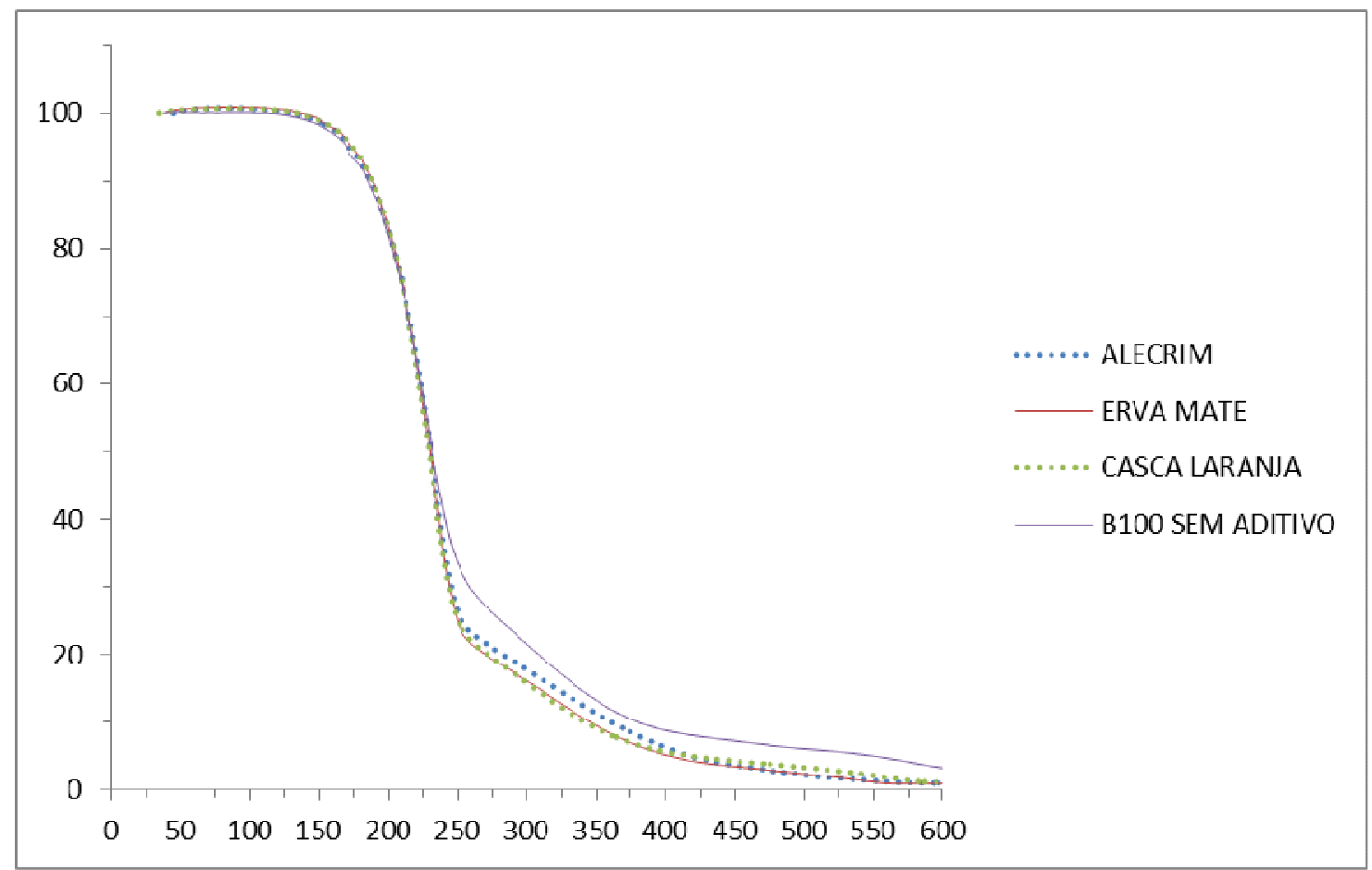

Figura 3 - TGA do B100 de canola puro e com $2.000 \mathrm{mg} / \mathrm{L}$ de aditivos no $60^{\circ}$ dia.

\section{CONCLUSÃO}

Pelas curvas TGA observa-se que o biodiesel de canola quando exposto a temperatura de $60{ }^{\circ} \mathrm{C}$ sofreu oxidação;

Amostras do B100 de canola expostas à temperatura de $60{ }^{\circ} \mathrm{C}$ indicam que dentre os extratos vegetais estudados o extrato da casca da laranja na concentração $2.000 \mathrm{mg} / \mathrm{L}$ apresenta o melhor comportamento antioxidante, pois os valor de Ti se apresentou maior no $60^{\circ}$ dia.

\section{REFERÊNCIAS}

ANAGNOSTOPOULOU, M. A.; KEFALAS, P.; KOKKALOU, E.; ASSIMOPOULOU, A. N.; PAPAGEORGIOU, V. P. Analysis of antioxidante compounds in sweet orange peel by HPLC-diode array detection-electrospray ionization mass spectrometry. Biomedical Chromatography, v. 19, p. 138-148, 2005.

ATABANI, A.E.; SILITONGA, A.S.; BADRUDDIN, I. A.; MAHILA, T. M. I., MASJUKI, H. H.; MEKHILEF, S. A compreensive review on biodiesel as an alternative resource and its caracteristics. Renewable and Sustainable Energy Reviews, v. 16, p. 2070-2073, 2012. 
CHAI, M. Thermal decomposition of methyl esters in biodiesel fuel: Kinetics, Mehcanisms and Products. 193f. Tese (Doutorado em Filosofia) - Escola de Energia, Meio Ambiente, Biológicas e Engenharia Médica - Universidade de Engenharia e Ciência Aplicada. 2012.

KOH, M. Y.; GHAZI, T. I. M. A review of biodiesel production from Jatropha curcas L. oil. Renewable and Sustainable Energy Reviews, v. 15, p. 2240-2251, 2011.

ATADASHI, I. M.; AROUA, M. K.; AZIZ, A. A. High quality biodiesel and its diesel engine application: A review. Renewable and Sustainable Energy Reviews, v. 14, p. 1999-2008, 2010.

SILVA, C. L. M. Obtenção de ésteres etílicos a partir da transesterificação do óleo de andiroba com etanol. 78 f. Dissertação (Mestrado em Química) - Universidade Estadual de Campinas. Campinas SP, 2005.

JAIN, S.; SHARMA, M. P. Stability of biodiesel and its blends: a review. Renewable and Sustainable Energy Reviews. v. 14, p. 667-678, 2010.

PAIVA, E. J. M. Estudo da produção de biodiesel a partir de óleo de babaçu e etanol utilizando a transesterificação alcalina tradicional com agitação mecânica e assistida por ultrassons. $173 \mathrm{f}$. Dissertação (Mestrado em Ciências do Programa de Pós-Graduação em Engenharia Química) Escola de Engenharia de Lorena - Universidade de São Paulo. Lorena - SP, 2010.

PALLEROS, D. R. Experimental Organic Chemistry. Santa Cruz: John Wiley, 1999. 836 p. 